\title{
O FISCO, HERDEIRO UNIVERSAL
}

\section{JOSE SALDANHA DA GAMA E SILVA}

SUMARIO: Evolução do tributo sôbre a transmissão da propriedado causa-mortis. $O$ Direito Romano. O Direito Medieval. O Direito Colonial Português, $O$ Direito Pátrio e a descentralização pelos Estados. Tendências legislativas: ascensão do fisco na ordem de vocação hereditária. Herança jacento e o Decreto-lei n.0 1.907, de 1939.

Evolução do tributo sôbre a transmissão da propriedade - A Administração Pública, já hoje um aspecto vivo da cultura humana, segue pari-passu o progresso social, provocando-o aqui, servindo-lhe de instrumento ali, consolidando-o acolá. Se quisermos ilustrar esta afirmação com fenômenos concretos, dificilmente encontraremos melhor seara do que a semeada pela moderna atuação do fisco. Ponte de ligação entre o Estado e o indivíduo, baliza insuspeita de todos os lances sociais, agindo sempre como uma indefectivel passerelle entre a bôlsa privada e as arcas do Tesouro, representa o fisco quase sempre a medida exata do estágio social de qualquer povo. Manejando, capcioso, a sua intrincada rêde de tributos, avança e recua maneiroso, seguindo paciente o fluxo e o refluxo das marés ideológicas.

Dentro dos tributos que melhor ilustram as nossas afirmações, podemos destacar o atual impôsto de transmissão da propriedado causa-mortis, cujo comportamento - sob certos aspectos, expressão viva das conquistas socialistas - chegou por fim, cautelosamente, a ir abrindo caminho para novas ordeng da vocação hereditária, nas quais o fisco gradativamente vem subindo.

Como sabemos, ainda depois de morto o homem atual se identifica com sua riqueza. Isto seria um paradoxo, se as leis não lhe possibilitassem a faculdade de dirigir sua fortuna post-mortem, tutelando-a por meio de suas Gltimas disposições a respeito. Daí os dois tipos distintos de sucessão causamortis: a testamentária e a natural (ab-intestato). Usando geralmente de um testamento (público, cerrado ou particular), ou mesmo de um codicilo (escrito particular que às vêzes substitui testamento), o de cujuus possibilitará uma sucessão testamentária. Se não se houver manifestado, teremos a sucessão abintestato, na forma da lei.

De um modo ou doutro, estaremos em face de legitimas transmissóes de propriedade. E, então, o fisco desperta, colhendo o herdeiro ou o beneficiário.

$E$ certo que a tese jurídica que a respeito pode nortear uma política fiscal ter sido distendida pelos mais extremados polos. Oscilando entre os preceiton de direito privado $e$ os preceitos de direito públioo, a sucessão causa- 
mortis é como uma encruzilhada esquiva, onde os pressupostos de um e outro direito se vão tanger. De um modo geral, porém - e embora contrariando a opinião dos mais ilustres civilistas ${ }^{1}$ - ainda aqui a diretriz máxima tem descambado pela precedência do direito público. Pode mesmo dizer-se que dificilmente encontraríamos um exemplo tão frisante para ilustrar aquêle célebre brocardo de BACON - Jus privatum sub tutela juris publicis latet. Fenômeno de verticalíssima repercussão social - já que possibilita a inte:rençấo do Estado na redistríbựçāo da riqueza - a sucessão tem merecido tratamento filosófico de quase todos os grandes juristas do passado - tratamento que procura, por ilações doutrináriass, explicar a atuação do fisco frento so espólio e ao herdeiro.

No secúlo XIX, por exemplo, podemos discernir duas correntes antagóaicas, ambas pressurosas em fundamentar o impôsto de sucessão causa-mortís. A primeira, de BENTIAM, que via no tributo apenas o pagamento pelos serviços prestados pelo Estado com o objetivo de regular as heranças e os legados. A segunda, de Bluntschli, WAGNER, ELY e outros, que vêen no tributo um remanescente das práticas feudais - ciosos todos êles da subrevivência do poder de domínio eminente do Estado, de base estritamente medieval.

Já hoje a questão parece estar restrita à discussão de um fundamento que perdeu todo seu interêsse filosófics, apresentando-se rudemente fiscal: a rucessão implica apenas num incremento de renda, para os beneficiados. $\mathrm{E}$ como tal, há um lídimo dever fiscal a reverènciar, cujo cumprimento o triburo facilita... E a teoria de um Graziani, de um ADaMs, de um Seligman, etc., para os quais a sucessão causa-mortis perdeu todo 0 seu aspecto solene-religioso, devendo ser o impôsto correspondente considerado como um preço pelo privilégio da sucessão, facultado pelo Estado...

Não se pode negar, todavia, que tôda a evolução filosófica do impôsto perderia sua significação se a política administrativa do tributo não se tivesse concretizado na prática fiscal. E mesmo interessante notar que o fisco como que, por vêzes, se tem adiantado às discussões filosóficas, cioso da sua longa experimentação a respeito.

Tentemos, pois, aqui, levantar alguns fatos administrativos que nos pareceram fundamentais à vida do impôsto de sucessã'o, que, afirmando-se mais e mais nos esquemas tributários poderosos (lembre-se que na Inglaterra de -ntes da guerra o tributo tendia cêrca de $10 \%$ da renda nacional), se identiLiea to como um legítimo direito sucessório do Estado, já hoje legando wo fisco o caräter de vero herdeiro universal. ${ }^{2}$

O Direito romano. O Direito medieval - O atual impôsto de transmissão da propriedade causa-mortis não é uma inovaçāo. Muito ao contrário, uas raízes se perdem muito além. Conta mesmo LoMrroso que ao tempo dos légidas uma lei egípcia criou expressamente o impôsto sôbre a sucessão. O mesmo aconteceu também com os romanos, cujo direito pretorial consignava uma taxa, paga com fundamento nos serviços que o Estado dizia prestar, vigilando o patrimônio vago. A evolução do gravame, já na própria Roma, se verificou de maneira a não deixar dúvidas de que ali realmente está o embrião do atual impôsto. E que se até o ano $40 \mathrm{~A}$.C. O herdeiro era encarado cmo um intangível sucessor da personalidade do de cujus, apropriando-se

1 Marcel Planiol e Grorges RIPpert, por exemplo, em seu Traité Pratique de Droit Civil Français, tomo IV (Successions), Paris, 1928, a págs, 10, escrevem que a legislaçäo fiscal tem mudado sempre em proveito do fisco. "O Estado", dizem êles, "encontrando a matéria tributável relativamente fácil de apreender, não tem cessado de aumentar êstes Aireitos, que terminaram por tomar o caráter de um verdadeiro confisco".

2 O nosso Código Civil baseia a Sucessão do Fisco em bases estratas de juro herediurio, nāo de jure occupationis. 
do patrimônio em funçāo do instituto da usocapio pro herede, a Lex Falcidia, daquele ano, visanda o sustento da guerra contra Pompéia, destinou ao Tesouro uma parte de cada herança transmitida ab-intestato. Coube a Augusto, todavia, 45 anos mais tarde, estabelecer o impôsto em bases mais ślidas, criando a vicessima hereditaturn, que recaía não só sôbre os herdeiros ab-testato ou ab-intestato, mas também sôbre os legatários. Êste gravame, que representava $20 \%$ da herança, permaneceu inalterável em tôda sua vigência, com exceção do tempo do imperador Caracalla, em que subiu a $16 \%$.. E nem se diga que o impôsto, jầ àquela época, não sofria a influência das injunções sociais; pois que, como nos conta CuQ, o tributo chegou a tomar foros de instrumento de contrôle social," a agir como penalidade contra os celibatários e casais sem filhos, como se pode depreender da Lex Julia de maritandis ordinibus a a Lex Papia Poppea.

O direito sucessório medieval, no entanto, foi muito diverso do romano. O característico básico do feudalismo - confusão dos direitos do proprietário - do suzerano - iria permear todo o arcabouço jurídico a respeito. Assim, morto o proprietário, prevalecia o suzerano. E o herdeiro só tomava posse da herança mediante novo contrato, novas solenidades, nova investidura. Foi assim até o século XIII, como se pode provar pelo direito medieval francês. Não havia impôsto de sucessão, como hoje o entendemos, porque não havia tal figura jurídica caracterizada nos moldes atuais. Havia, contucio, um pagamento pela transmissão - um tributo que era mais um símbolo - chamado acopte, nuns lugares, esporle, nautros, ou, ainda, arrière acopte.

Só depois de desvanecidos os últimos vestígios do feudalismo em França é que surgiu o impôsto sôbre a sucessão causa-mortis - le droit de centièmo dernier, estabelecido por Luís XIV, o qual chegou a ter um aparelho administrativo bastante evoluído. E que já então se voltara a prezar a inviolabilidade dos laços familiais, à maneira romana. Principia a herença a passar diretamente ao herdeiro, voltando a vigorar o velho brocardo romano - solus Deus heredem facere potest.

Mais tarde burgo a faculdade de testar a favor da Igreja : eram os testamentos pro bono ot remedio animze sure, que tinha por fim invocar a benevolência divina em favor do de cujus.

O Direito colonial português - Em Portugal, onde podemos situar o inicio da história do nosso atual impôsto, os fenômenos se passaram da mesma forma. A sucessão era como que um fenômeno sagrado; o fisco não a molestava. Mas também aqui as lides administrativas vão influir na parte doutrinária do tributo: surgiram desmandos por parte das autoridades incumbidas de efetuar a transmissão de tal monta que obrigaram o Estado a tomar medidas de tutela, já que os provedores e oficiais de defuntos e ausentes, principalmente os de ultramar, começaram a se beneficiar durante o serviço administrativo da operação, desviando bens, confundido os herdeiros, exigindo polpudas gratificações, etc. ${ }^{b}$. Começava, assim, ainda que tímida, a intervenção do Estado na política sucessótia. A reforma, porém, com tôda sua ramificação do efeitos econônicos, acabou por influenciar o ânimo do rei lusitano. $\mathrm{E}$ assim, apó a ascensão de Urbatso VIII, em 1623 - que era visto como um sibarita - a reação recrudesce, tomando o govêrno medidas contra os herdeiros que portencesmen ao clero.

. Cro, Mraval nes Institutions Juridiques des Romains, Paris, 1917, pág. 138.

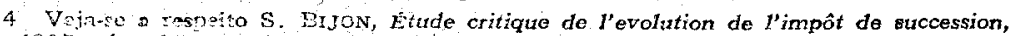
Paris, 1927 , pág. 10 comintes.

5 A nosso fimacáo é fecinnente comprovada pelas leis que a Metrópole teve que baicor a carta-régia do 31 de outubro de 1504 ; a cartarrégia de 30 de março de 1606 , a carta-régia de 24 de maro de 1508 e outras, pelas quais se tomavam medidas prevenindo os Etousos registradw. 
Por êsse motivo, como que se quebrou a tradição que fazia da herança um tabu. Data daí a crescente desenvoltura do fisco português em face do patrimônio a transmitir, até que em 1809, pelo alvará de 17 de junho, que ampliou o impôsto do sêlo, foi criada uma "porção imposta" às heranças e legados "que não proviessem de ascendentes ou descendentes", porção que foi calculada em $1 / 10$ da herança (sem dúvida com inspiração no impôsto mais popular na época - a décima), podendo ser aumentada para $1 / 5$, em se tratando de parentes "fora do segundo grau".

O tributo representava uma dívida particular do herdeiro, tomando desde logo o caráter de impôsto pessoal.

O Direito pátrio e a descentralização pelos Estados - O caso brasileiro continua o caso português sem nenhum sobressalto. Libertado da Metrópole, tentou o país, logo em 1832 , nova classificação da nossa renda nacional que passou a ser dividida em geral e provincial. Ficou estabelecido que o impôsto de sucessão ficaria adstrito à alçada local, passando, pois a integrar a renda provincial.

Em 1842, após o Decreto n. ${ }^{\circ} 156$, de 28 de abril, fruto do Visconde de Arantes, o impôsto teve seu mecanismo administrativo grandemente ampliado. Por êste dispositivo, o Estado foi equiparado a vero credor privilegiado, como se deduz do seu art. $4 .^{\circ}$ :

"Feito o têrmo de encerramento do inventário, se procederá à liquidação do quanto se dever à Fazenda Nacional da taxa de herança ou legados; e pela importância desta taxa se contemplará a Fazenda Nacional como qualquer dos herdeiros para a respectiva partitha, e nesta se the adjudicaräo dos bens inventariados os que necessários forem para o seu pagamento, exceto o caso de serem as heranças ou legados de usufruto".

Estava lançada, como se vê, a partida que iria desenvolver-se progressivamente, possibilitando ao Estado cada vez maior desenvoltura contra o espólio, de tal maneira que o fisco chegou por fim a infiltrar-se cada vez mais audacioso nas clássicas ordens de vocação dos herdeiros.

Em 1860, por exemplo, o Decreto n. 2.708 , de 15 de dezembro, que reafirma o caráter pessoal do impôsto, precisa com maior segurança o que é ativo de sucessão, liquído das dívidas, encargos com funerais, etc., chegando mesmo o art. 12 a estatuir expressamente que o Procurador da Fazenda podia requerer a fromataça da espólio de tantos bens quantos fôssem nocessários para o pagamento do impósto.

Em 1874, está outro marco fundamental para - o impôsto de transmissão da propriedade causa-mortis a qual já então aparece encarada sem nenhum laivo religioso, em têrmos exclusivamente jurídicos.

O Decreto n. 5.581 , de 31 de março, veio equiparar a transmissão causamortis à transmissão inter-vivos, tangendo as duas matérias, até então legisladas independentemente. Mas não parou aí. O \$ $10^{\circ}$ do art. 27 declarou textualmente que, em "sendo os bens imóveis, o impôsto constitui ônus real", reformando fundamentalmente o crivo do impôsto.

As tabelas anexas ao decreto provavam sem rebuços a expansão do tri'buto. Se se tratasse de herdeiros necessários em linha reta, o impôsto era de $1 / 10 \%$ da herança; subindo a $10 \%$ em caso de primos e avós, e a $20 \%$, em tratando de sucessor estranho.

Para a transmissão inter-vivos, a tabela ia também de $1 / 10 \%$ para os herdeiros necessários, até $6 \%$, para estranhos.

Assim, de $20 \%$, limite para transmissão causa-mortis, chegava-se apenas a $6 \%$, para trasmissäo inter-vivos. E por que? Porque de 
$6 \%$ era a taxa para os contratos de compra e venda comercial... Como se vê, por medidas simplesmente administrativas, a sucessão inter-vivos foi equiparada, pelo fisco, ao simples contrato de compra e venda, cuja tara, ainda que se tratasse de adjudicação ou arrematação, era de $6 \%$. Dessa maneira, como teòricamente se pode equiparar a sucessão causa-mortis à sucessão inter-vivos, aquela, ainda que de um ângulo meramente edministrativo, acabou sendo equiparada a mero contrato de compra e venda...

E pôde o fisco apresentar-se como um credor impenitente, cujo apetite crescia na razão inversa do grau de parestesco dos herdeiros, chegando êle próprio a funcionar como um herdeiro oficioso.

Cumpre notar que no Brasil êstes privilégios se transferiram para os Estados, quando a Carta de 1891 distendeu o impôsto pélos sistemas tributários locais, embora os constituintes não sentissem muito interêsse por tal fonte de renda, como os pessimistas Coklho e Campos e José Higino.

Os Estados, porém, recebida a vantagem, entraram a usá-la com sofreguidão, sobrecarregando desmedidamente as taxas do impôsto, chegando por vêzes quase ao confisco pregado pela corrente socialista de STUART-MILL. Disto redundou que o tributo terminou por ter uma feição própria em cada unidade da federação, embora algumas tímidas tentativas de regulamentação, em bases nacionais, surgissem de quando em vez.

Eis por que num mesmo país encontramos para o impôsto de sucessão três diretrizes diversas: nuns Estados, a tributação apela para o monte partilhável; noutros, apenas para as cotbs hereditárias; e noutros, ainda, para o monte e as cotas.

Dêsse modo, se o art. 8. $^{\circ}$ do Código Tributário de Pernambuco (Decreto n. 473, de 20-340), determina que "para o cálculo do pagamento do impôsto tomar-se-á por base o total da herança partilhável"; per contra o Decreto-lei n. $0^{\circ} 224$, de 23 de maio de 1940 , suprimiu para o Distrito Federal o impôsto global sôbre a herança, insistindo, ao contrário, sòmente no impôsto progressivo sôbre os quinhões e os legados. Enquanto isso, Estados como a Paraíba continuam gravando não só o monte a partilhar ou adjudicar (taxa de $1 \%$ ), como também as cotas hereditárias (tabela determinada pelo Decreto n. ${ }^{\circ} 40$, de 12 de março de 1940).

Absolutamente livres, continuaram os Estados, entre outros enganos, acordes em tributar com certa voracidade a transmissão causa-mortis, enquanto que se mantinham com grande benevolência frente às transmissōes inter-vivos, negando, pois, a evolução filosófica que se manifestara pela equiparação dos dois fenômenos, situação que continuou possibilitando a fraude e a sonegação por meio de fantásticas transmissões inter-vivas.

Se confrontarmos as tabelas das taxas que vigoram ainda hoje em alguns dos nossos Estados, veremos que, fruto desta política de miopia, em se tratando de herdeiros estranhos, a taxa varia em médias bastante elevadas. Assim, ainda hoje, se S. Paulo, benevolente, cobra 12,6\%, Paraná sobe a $40 \%$ e Minas Gerais a $50 \%$ (Decreto-lei estadual n. 67, de 20 de janeiro de 1938).

Não se esqueça também que, em alguns Estados, como S. Paulo e Paraná, quando se cogita de grandes fortunas, a evasão chega a ser clamorosa, pois que, naqueles Estados, em se tratando de fortunas superiores a ........... Cr\$ 5.000.000,00, as tabelas para o impôsto de transmissão causa-mortis continuam a ser progressivas, ao contrário das tabelas para o impôsto de transmissão inter-vivos, que passam a ser regressivas.

Como se vê, êstes são todos grosseiros erros administrativos que ainda hoje merecem um corretivo. Prevenindo tais disparates é que a constituinte de 1934 havia tentado abrir a campanha para despertar a letargia da União em face dos fenômenos da transmissão causa-mortis. 
Glosando as idéias de Montesquieu, Augusto Comte, STUART-MnL e outros - fervorosos inimigos da sucessão intestada - até às idéias dos mais avançados socialistas modernos, que pregam a falência de qualquer sucessão que não seja a do Estado, alguns constituintes tentaram, naquela época, limitar a nossa vocação hereditária, como Pereira Lira e Osório Borba, que propuseram uma vocação hereditária que ocorresse "estritamente na linha reta ou entre cônjugues", isto porque estavam convencidos de que, na realidade, os laços familiais "se desvanecem dia a dia".. 6

Não era fácil, porém, vencer os corifeus da corrente fortemente conservadora, chefiada por Euvaldo Lodi e Alde Sampaio. E o impôsto continuou sem qualquer significação social, entregue a um destino em cada Estado e - uma taxa em cada caso.

Porque parecesse impossível uma reforma que unificasse a orientação do impôsto, a Constituição de 1937 balbuciou a mesma política não intervencionista de 1934. O impôsto continuou com uma base legal única - conseitucional - mas se perdia em refraçōes diversas para cada Estado, sempre, porém, carecente de uma política mais avançada para sua aplicação.

Tendências legislativas:ascensão do fisco na ordem de vocação hereditária - Fruto mesmo dêsse afã de melhor distribuir a riqueza, as tendências socialistas têm levado os países mais avançados a intervir na sucessão causamortis, restringindo-a abertamente. Se no direito romano a sucessão se processava através das cadeias do. sangue - e isto, porque, dentro da família, o pater se identificava com o próprio Estado - já no direito canônico a Igreja toma a si o contrôle de tais fenômenos. E se, após a reforma, o físco hostiliza o herdeiro do clero, hoje avançou muito além, hostilizando o próprio herdeiro familial. Assim, a sucessão perde dia a dia seu caráter solene, estereotipada como qualquer singela transmissão de propriedade.

Por outro lado, a linha evolutiva da atuação do fisco em face do espólio também parecia ter em todo o mundo atingido o maximum-sensibile, mediante completos aparelhos administrativos. Foi mesmo êste aspecto que um especialista da matéria WILLIAM SchulTz, ? visou, quando escreveu "podemos hoje considerar o estágio experimental do impôsto de sucessão como terminado. Tanto os tratadistas como os legisladores 0 aceitam como a valiosa fonte de uma apreciável parcela das rendas tributárias".

A verdade, porém, é que ainda hoje o Estado tem procurado avançar mais: esgotada a capacidade fiscal via tributos, começa o fisco a lançar-se mais abertamente à aventura de cercear êle próprio a faculdade privada de herdar, apresentando-se a si mesmo na qualidade de herdeiro.

No Brasil, por exemplo, contrariando a arraigada tradição do Fiscus post omnes, o Estado, por meio de um sistemático e paulatino afastamento dos herdeiros mais longínquos, vai conseguindo infiltrar-se maneirosamente através da tabela dos sucessores, sem ferir grosseiramente a "consolidação da sociedade doméstica", pregada pelos nossos mais caros juristas. Dessa maneira, já em 1907, a lei n..$^{\circ} 1.839$, de 31 de dezembro, modificou grandemente a nossa política a respeito. A vocação hereditária passou a ser:
a) descendentes:
b) ascendentes;
c) cônjuge sobrevivente;
d) colaterais, até o $6^{\circ}$ grau;
e) o fisco.

6 Anais da Assembleia Nacional Constituinte, 1934, vol. XXI, pág. 306.

7 William J. Schultz, Inheritance taxation, em Encyclopoedia of the Social Sciencas. 
Por esta lei os colaterais, que até então vinham à vocação até o $10^{\circ} \mathrm{grau}$, como pregava o direito canônico, foram restritos - ao $6^{\circ}$-grau; por outro lado, ficou assegurada a sucessão do fisco, que para se efetivar na posse da herança bastava apenas lavrar um "sentença de vacância" que declarasse "os bens vagos e devolutos à Fazenda".

$E$ as restrições não pararam aí. O Código civil, surgido nove anos mais tarde, se por um lado concordava, pelo art. 1.605, em chamar à sucessão os descendentes legitimados, per contra estipulou que, na sucessão dos colaterais os mais próximos excluiriam os mais remotos, sem distinção de sexo ou idade, salvo o direito de representação concedido aos filhos de irmãos. Este direito de representação, porém, só se daria em linha reta descendente, nunca na ascendente. Na linha transversal, segundo o art. 1.622 , só se dá o direito de representação, em favor dos filhos de irmãos do falecido, quando com irmão dêste concorrerem. Os representantes só podem herdar, como tais, o que herdaria o representado, se vivesse.

Herança jacente e o Decreto-lei n. 1.907 , de 1939 - A tendência de limitar a nossa agnitio bonorum possessionis, porém, em 1939, mais claramente iria desnudar-se no Decreto-lei n. 1.907 , de 26 de dezembro, que, dispondo sôbre a herança jacente, limitou a sucessão dos colaterais sòmente aos irmãos, isto é, até o $2 .^{\circ} \mathrm{grau}$.

A herança jacente, isto é, a afirmação de que o patrimônio não passa diretamente ao herdeiro, ficando sob tutela do Estado, por si só é uma convidativa porta aberta à chamada do fisco à sucessão. Mas êste vem ainda empolgando outros setores, como se vê por esta outra medida revolucionária, adotada pelo Decreto citado, e que diz respeito ao prazo referente à vacância da herança: enquanto o art. 1.594, de nosso Código, estatuía o prazo de 30 anos, o referido decreto estipulou que êste prazo fôsse abreviado para 6 meses desde a morte do de cujus, "decorridos os quais sem que os aludidos herdeiros se habilitem à sucessão, os bens serão considerados vacantes".

Outro ponto também significativo é a confusão dos prazos para decretação da vacância e absorção da herança pelo Estado. Pelo art. 1.593 do Código Civil, a declaração de vacância só teria lugar depois de um ano do término do inventário. Só contados 30 anos da abertura da sucessão é que os bens arrecadados passariam ao domínio do Estado ou do Distrito Federal, se não fôssem reclamados pelos herdeiros. O decreto citado, porém, confere prescriçāo de qualquer ação contra a herança, também no prazo de 6 meses, findos os quais "não mais se admitirá habilitação de herdeiros, legitimos ou testamentários". E lembre-se mesmo que, no sentido de salvaguardar os bens que possivelmente irão integrar o patrimônio do Estado, o art. $30^{\circ}$ do mesmo decreto vedou tôda sorte de ônus sôbre a herança jacente, quer federal, estadual ou municipal, salvo os de custas e despesas judiciais devidas a funcionários não remunerados.

Como se percebe, já hoje o fisco se apresenta na qualidade de legítimo herdeiro: declarada a vacância, diz textualmente o decreto, a herança defere-se à União, onde quer que haja sido domiciliado o de cujus, arrecadando-se. - espólio como renda eventual que, segundo um avançado critério socialista, deverá ser empregada em obras de proteção à família. Dessa maneira, vemos - Brasil na vanguarda das nações mais progressistas, chegando mesmo, ainda que por um imperfeito aparelho administrativo, a elevar o Fisco à categoria de sucessor universal, realizando, pois, na prática, a velha idéia dos exegetas franceses, como HUC e DEMOLOMBE.

$\leftarrow$ certo que com estas medidas não se cogita de hostilizar a propriedade privada. Nem se pense que se pretende excluir a sucessão legítima, o quo só cetia viável pela extinção radical da propriedade privada. Isto, porque, 
na realidade, ainda que se atinja um grau muito avançado de socialismo, enquanto prevalecerem vestígios dos regimes de economia burguesa, os herdeiros legítimos continuarão contribuindo muitas vêzes para a formação da fortuna deixada pelo de cujus. Daí, até autores como Vinali ${ }^{8}$ haverem declarado que a "sucessão legítima é uma necessidade social".

Tendo em vista esta doutrina é que o direito brasileiro sempre tomou medidas acautelatórias, como assegurar aos herdeiros legítimos um remanescente da herança - que só em parte pode ser legada; prevenir a deserdação, exigindo a declaração expressa para tal procedimento; etc.

Não há negar, porém, que a sucessão causa-mortis continua sendo um dos pontos mais visados peles socialistas militantes, seguindo a evolução do próprio conceito de Estado.

Está hoje comprovado que os sistemas de govêrno variam numa larga faixa, que vai do estado absolutamente liberal, cujo sistema econômico é individual, até o estado absolutamente totalitário, cujo regime econômico é estatal. Como fórmulas evolutivas, temos: de um lado, saindo do extremo liberal, as democracias capitalistas de hoje, como a Inglaterra e os Estados Unidos; de outro lado, saindo do extremo totalitário, aș democracias socialistas, como a Rússia.

Estas duas subfórmulas caminham, afinal, para uma fórmula única de conciliação, que seria uma espécie de síntese hegeliana.

Do mesmo modo, a transmissão da propriedade causa-mortis varia numa faixa que vai da transmissão direta aos sucessores agnados, à transmissão direta e total ao Estado. E também aqui é mister caminharmos para uma síntese de conciliaçã ?. Tudo faz crer, porém, que esta síntese deverá ser, não apenas a resultant de um abstrato arcabouço jurídico, mas de um incoercível evolucionismo sonômico. 